\title{
Noradrenergic modulation of intrinsic and synaptic properties of lumbar motoneurons in the neonatal rat spinal cord
}

\section{Maylis Tartas 1,2, France Morin'2, Grégory Barrière' ${ }^{1}$, Michel Goillandeau' ${ }^{1}$, Jean-Claude Lacaille ${ }^{2}$, Jean-René Cazalets $^{1}$ and Sandrine S. Bertrand ${ }^{1 *}$}

CNRS UMR 5227, Université de Bordeaux, Bordeaux, France

2 Département de Physiologie, GRSNC, Université de Montréal, Montréal, QC, Canada

\section{Edited by:}

Eve Marder, Brandeis University, USA

Reviewed by:

Roland L.Calabrese, Emory University, USA

Ole Kiehn, Karolinska Institutet,

Sweden

\section{*Correspondence:}

Sandrine S. Bertrand, Université Victor Ségalen (Bordeaux 2) Zone Nord, Bât. 2A/B; 146, rue Léo Saignat, 33076

Bordeaux Cedex, France.

e-mail: sandrine.bertrand@ u-bordeaux2.fr
Although it is known that noradrenaline (NA) powerfully controls spinal motor networks, few data are available regarding the noradrenergic (NAergic) modulation of intrinsic and synaptic properties of neurons in motor networks. Our work explores the cellular basis of NAergic modulation in the rat motor spinal cord. We first show that lumbar motoneurons express the three classes of adrenergic receptors at birth. Using patch-clamp recordings in the newborn rat spinal cord preparation, we characterized the effects of NA and of specific agonists of the three classes of adrenoreceptors on motoneuron membrane properties. NA increases the motoneuron excitability partly via the inhibition of a $K_{\mathbb{R}}$ like current. Methoxamine $\left(\alpha_{1}\right)$, clonidine $\left(\alpha_{2}\right)$ and isoproterenol $(\beta)$ differentially modulate the motoneuron membrane potential but also increase motoneuron excitability, these effects being respectively inhibited by the antagonists prazosin $\left(\alpha_{1}\right)$, yohimbine $\left(\alpha_{2}\right)$ and propranolol $(\beta)$. We show that the glutamatergic synaptic drive arising from the T13-L2 network is enhanced in motoneurons by NA, methoxamine and isoproterenol. On the other hand, NA, isoproterenol and clonidine inhibit both the frequency and amplitude of miniature glutamatergic EPSCs while methoxamine increases their frequency. The T13-L2 synaptic drive is thereby differentially modulated from the other glutamatergic synapses converging onto motoneurons and enhanced by presynaptic $\alpha_{1}$ and $\beta$ receptor activation. Our data thus show that the NAergic system exerts a powerful and complex neuromodulation of lumbar motor networks in the neonatal rat spinal cord.

Keywords: spinal cord, motoneuron, noradrenaline, synaptic drive, noradrenergic receptors, $\mathrm{K}_{\mathrm{IR}}$ current

\section{INTRODUCTION}

In all vertebrates including humans, the descending noradrenergic (NAergic) pathways, originating from the pons, have been shown to initiate and facilitate the expression of spinal locomotor output (Jordan et al., 2008) and to modulate the segmental reflexes (Kitazawa et al., 1985; Jankowska et al., 1998). In the chronic spinal cat, the NAergic compounds were found to be the most effective pharmacological agents in initiating locomotion (Forssberg and Grillner, 1973; Kiehn et al., 1992; Chau et al., 1998a; Barbeau and Norman, 2003). Furthermore, the NAergic precursor L-DOPA has been shown to induce coordinated air stepping in intact or spinal rat pups (Van Hartesveldt et al., 1991). Evidence regarding the role of NAergic modulation in locomotor networks has also been provided in in vitro preparations (Merrywest et al., 2002; Rauscent et al., 2009). In the isolated spinal cord preparation from newborn rats, noradrenaline (NA) induces a slow non-locomotor rhythm but appears to be a potent modulator of the ongoing locomotor rhythm (Kiehn et al., 1999; Sqalli-Houssaini and Cazalets, 2000; Gordon and Whelan, 2006).

All NAergic receptors are G-protein coupled receptors that can be divided into three main classes: three $\alpha_{1}$-receptors $\left(\alpha_{1 \mathrm{~A}}, \alpha_{1 \mathrm{~B}}, \alpha_{1 \mathrm{C}}\right)$, three $\alpha_{2}$-receptors $\left(\alpha_{2 \mathrm{~A}}, \alpha_{2 \mathrm{~B}}, \alpha_{2 \mathrm{C}}\right)$ and three $\beta$-adrenoreceptors $\left(\beta_{1}, \beta_{2}\right.$, $\beta_{3}$ ) (Hein, 2006). Little information is available on the precise role of these receptors in the NAergic neuromodulation of spinal motor networks. In the spinal cat, activation of the $\alpha_{2}$ receptors by specific agonists strongly improves functional rehabilitation after spinal cord injury (SCI), while $\alpha_{1}$ receptor agonists appears less potent (Rossignol et al., 2001). By contrast, in the neonatal rat spinal cord, $\alpha$, receptor agonists induce motor activity and boost ongoing fictive locomotion while $\alpha_{2}$ and $\beta$ receptor agonists solely slow down the chemically induced fictive locomotion (Sqalli-Houssaini and Cazalets, 2000)

Collectively, these studies underlie the important neuromodulatory role of the NAergic system in the physiology and pathophysiology of the spinal motor neuronal networks. Paradoxically, few data are available regarding the modulation of intrinsic and synaptic properties sustaining the excitatory action of NA in motor networks.

Taking advantage of the knowledge accumulated on the organization of the lumbar motor network in the isolated spinal cord preparation of the newborn rat, our study provides the first detailed analysis of the cellular basis of the NAergic modulation in lumbar motor network. Patch-clamp experiments were conducted to precisely analyze the role of the three main types of adrenoreceptors in the modulation of the membrane properties and synaptic inputs of lumbar motoneurons.

\section{MATERIALS AND METHODS ETHICAL APPROVAL}

Experiments were performed using 115 Wistar rats aged 1-5 days (mean $2.4 \pm 0.1$ days) bred in our laboratory. All experiments were carried out in accordance with the guidelines of the Institutional Animal Care and Use Committee of Bordeaux 2 University. 


\section{ISOLATED SPINAL CORD PREPARATION}

The animals were chilled by hypothermia until reflexes were lost, then decapitated. A laminectomy was performed to remove the spinal cord. The spinal cord was cut at the thoracic level, placed in a recording chamber (approximate volume 5-6 $\mathrm{ml}$ ) and superfused $\left(2 \mathrm{ml} \mathrm{min}^{-1}\right)$ with oxygenated $\left(95 \% \mathrm{O}_{2}-5 \% \mathrm{CO}_{2}\right)$ physiological saline containing (in $\mathrm{mM}$ ): $\mathrm{NaCl} 130, \mathrm{KCl} 3, \mathrm{CaCl}_{2} 2.5$, $\mathrm{MgSO}_{4} 1.3, \mathrm{NaH}_{2} \mathrm{PO}_{4} 0.58, \mathrm{NaHCO}_{3} 25$, glucose 10 adjusted to $\mathrm{pH} 7.4$ with $\mathrm{HCl}$. All experiments were performed at room temperature $\left(25^{\circ} \mathrm{C}\right)$.

\section{SPINAL CORD PARTITIONING}

A Vaseline wall was built with a syringe at the junction between the lumbar 2 (L2) and L3 level so that the low lumbar spinal cord (L3, L4 and L5 segments) could be superfused separately from the thoracic 13 (T13)/L2 locomotor network. The water tightness of the wall was checked at the beginning and at the end of the experiment by filling the pool until a meniscus was created. If no changes in the saline level occurred after $5 \mathrm{~min}$, the wall was taken to be watertight.

\section{EXTRACELLULAR RECORDINGS AND STIMULATIONS}

The motor output was recorded in the differential mode from the ventral roots using extracellular stainless steel pin electrodes insulated with Vaseline. Locomotor-like activity was induced by bath applying a mixture of serotonin $(5-\mathrm{HT}, 18-20 \mu \mathrm{M})$ and $N$-methyl DL-aspartate (NMA, 18-20 $\mu \mathrm{M}$ ) on the T8-L2 segments.

\section{ELECTROPHYSIOLOGICAL METHODS}

Blind whole-cell patch-clamp recordings from the L4-L5 motoneurons were made using glass microelectrodes (15-20 M $\Omega$ ) filled with a solution containing (in $\mathrm{mM}$ ): $\mathrm{K}$-gluconate $120, \mathrm{KCl} 20, \mathrm{CaCl}_{2}$ $0.1, \mathrm{MgCl}_{2}$ 0.1, EGTA 1, HEPES 10, GTP 0.1, cAMP 0.2, leupeptin 0.1, $\mathrm{Na}_{2}$-ATP 3, and D-mannitol 77, $\mathrm{pH}$ 7.3. A liquid junction potential of $+15 \mathrm{mV}$ was experimentally determined (Neher, 1992) and records were corrected for this potential. Motoneurons were identified by antidromic action potentials in response to ventral root stimulation. Electrophysiological recordings were analyzed using the Axograph software program (Axograph Scientific, Sydney, Australia). To assess the motoneuron excitability, the average spike frequency was calculated by taking the mean interspike interval across a current step. To compute the mean synaptic drive, intracellular recordings were divided into single locomotor cycles based on the extracellular recordings (see Fig. 1c in Bertrand and Cazalets, 1999). Each isolated cycle was subsequently normalized (from 0 to $100 \%$ ) by resampling and the mean locomotor drive was calculated by averaging the data from at least 25 cycles.

Miniature excitatory postsynaptic currents (mEPSCs) were recorded using glass microelectrodes filled with a solution containing (in mM): $150 \mathrm{CsCl}, 1$ EGTA, $10 \mathrm{HEPES}, 0.1 \mathrm{CaCl}_{2}, 4.6$ $\mathrm{MgCl}_{2}, 2 \mathrm{ATP}$, and $0.5 \mathrm{GTP}$. A liquid junction potential of $+7 \mathrm{mV}$ was measured in these experimental conditions (Neher, 1992) and post hoc corrections of the membrane potential values were performed in accordance. Due to the very small amplitude of the mEPSCs (around $6 \mathrm{pA}$, see Section "Results"), recordings were filtered at $300 \mathrm{~Hz}$. Sequences of at least 5 min of synaptic activity were recorded at a holding potential of $-75 \mathrm{mV}$. The traces obtained were analyzed with an algorithm developed in the software program Labview (National Instruments, Austin, TX, USA). The threshold of mEPSCs was set by eye and varied depending on the RMS noise level of the recordings. Automatically screened mEPSCs were accepted or rejected based on visual inspection. Statistical analysis was performed using the Kolmogorov-Smirnov (KS) test for distribution differences. Significant differences in the mean amplitude and frequency were tested using the Student's paired $t$-test.

Series resistance (mean value: $28 \pm 1 \mathrm{M} \Omega, n=99$ neurons) was monitored throughout the experiments and was not compensated. Data were discarded if series resistance varied more than $\pm 20 \%$ of the initial value.

\section{DRUGS}

Fresh drug solutions of NA and of the NAergic agonists and antagonists were prepared daily and protected from light exposure. All other drugs were prepared at stock solutions, aliquoted and frozen until use. 6-cyano-7-nitroquinoxaline-2,3-dione (CNQX) was diluted in DMSO with a final concentration of less than $1 \%$.

\section{IMMUNOHISTOCHEMISTRY}

Wistar rats ( $n=2$, postnatal day 5$)$ were deeply anesthetized with sodium pentobarbital and perfused through the ascending aorta with freshly prepared fixative containing $4 \%$ paraformaldehyde (PFA) in phosphate buffer (PB 0.1 M). Spinal cords were dissected out and postfixed in the fixative solution for approximately $4 \mathrm{~h}$. They were thoroughly rinsed in $0.1 \mathrm{MPB}$ and cryoprotected in $30 \%$ sucrose overnight. Spinal cords were sectioned to isolate lumbar segments (L3-L5) and coronal sections ( $25 \mu \mathrm{m}$ thick) were cut on a freezing microtome (Leica SM2000R, Germany). Free-floating sections were processed for double immunofluorescence using polyclonal rabbit antibodies against (1) the alpha la adrenergic receptor (1:200, Sigma, Canada), (2) the alpha 2 a adrenergic receptor (1:200, Sigma, Canada) and (3) the beta 1 adrenergic receptor (1:250, Santa Cruz, CA, USA), and the goat anti-choline acetyltransferase (ChAT, 1:200, Millipore, CA, USA). Sections were then put in goat antirabbit IgGs conjugated to FITC (1:200) and donkey anti-goat IgGs conjugated to Texas red (1:200, Jackson Immunoresearch Inc.). To verify the specificity of the antibodies, controls were done by omitting primary antibodies and, in each case, no visible staining was detected. The pre-absorption of NA antibodies with their immunizing peptide also showed their specificity (Milner et al., 1998; Fauser et al., 2004; Queiroz et al., 2008).

\section{STATISTICAL ANALYSIS}

Statistical analyses were performed on raw data. For samples less than 10 neurons, statistical analyses were performed using non-parametric tests. Wilcoxon matched pairs or Mann-Whitney tests were used to compare two series of data. Kruskal-Wallis or Friedman one-way analysis of variance (ANOVA) were carried out to test for significant effects between the different drugs for unpaired or paired observations, respectively. Pairwise comparisons were performed using Dunn's post-tests. The level of significance was set at $p<0.05$. All data are expressed as mean \pm standard error of the mean (SEM) in the text and figures. Asterisks in the figures indicate positive significance levels and the numbers in histogram bars or in parenthesis refers to the number of neurons examined. 


\section{RESULTS \\ LUMBAR MOTONEURONS EXPRESS THE THREE MAIN CLASSES OF ADRENORECEPTORS AT BIRTH}

Previous studies using radioligand binding have shown that the $\alpha 1$ receptors are detectable in motoneurons as early as P1-P5 while the $\alpha 2 \mathrm{a}$ receptors are transiently expressed in rat motoneurons at high level during the embryonic and early postnatal periods. In contrast, few data are available concerning the expression of the $\beta$ receptors in motoneurons (for review see Rekling et al., 2000). Immunohistochemical labeling was then performed to determine whether the $\alpha_{1 \mathrm{a}}, \alpha_{2 \mathrm{a}}$ and $\beta_{1}$ receptors are expressed in lumbar motoneurons in early postnatal developmental stages. Immunolabeling of lumbar spinal cord sections revealed an $\alpha_{1 \mathrm{a}}$ (Figure 1A), $\alpha_{2 \mathrm{a}}$ (Figure 1B) and $\beta_{1}$ positive (Figure 1C, green immunofluorescence) immunoreactivity in large body neurons within lamina IX (dashed line in Figure 1). To determine whether these labeled cells were motoneurons, we characterized the phenotype of the NAergic immunopositive neurons by immunohistochemical staining of ChAT (Figure 1, red immunofluorescence). The merge panels in Figure 1 show that the large cell bodies in lamina IX were double stained for NAergic receptor subtypes and ChAT, therefore indicating that lumbar motoneurons express the $\alpha_{1 \mathrm{a}}, \alpha_{2 \mathrm{a}}$ and $\beta_{1}$ receptors at birth.

\section{NORADRENERGIC MODULATION OF THE MEMBRANE PROPERTIES OF THE L4-L5 LUMBAR MOTONEURONS}

To precisely assess the action of NA, we used two different concentrations of NA ( 5 and $50 \mu \mathrm{M}$ ) since it was previously suggested in the neonatal rat spinal cord that NA mediated excitatory or inhibitory effects on motor networks through the differential activation of $\alpha_{1}$ and $\alpha_{2}$ adrenoreceptors depending on its concentration (SqalliHoussaini and Cazalets, 2000). Furthermore we investigated the role of the different adrenoreceptors in the NAergic neuromodulation using specific agonists of the three classes of adrenoreceptors: methoxamine $\left(\alpha_{1}\right)$, clonidine $\left(\alpha_{2}\right)$ and isoproterenol $(\beta)$.

First, we tested the effects of NA on motoneuronal excitability in the presence of blockers of fast inhibitory (strychnine and bicuculline (10\% of experiments) or gabazine, $1 \mu \mathrm{M}$, Barriere et al., 2008) and excitatory (CNQX and AP5, $5 \mu \mathrm{M}$ ) synaptic transmission. In these conditions, NA induced a strong inward current in motoneurons held at $-75 \mathrm{mV}$ associated with a significant increase in the input membrane resistance computed from current-voltage curves, when bath-applied at both $5 \mu \mathrm{M}$ (Figure 2A and Table 1) and $50 \mu \mathrm{M}$ (Table 1). When switched to current clamp conditions, NA depolarized all motoneurons tested $(n=16)$ beyond spike threshold at both low and high doses (data not shown). To determine whether NA
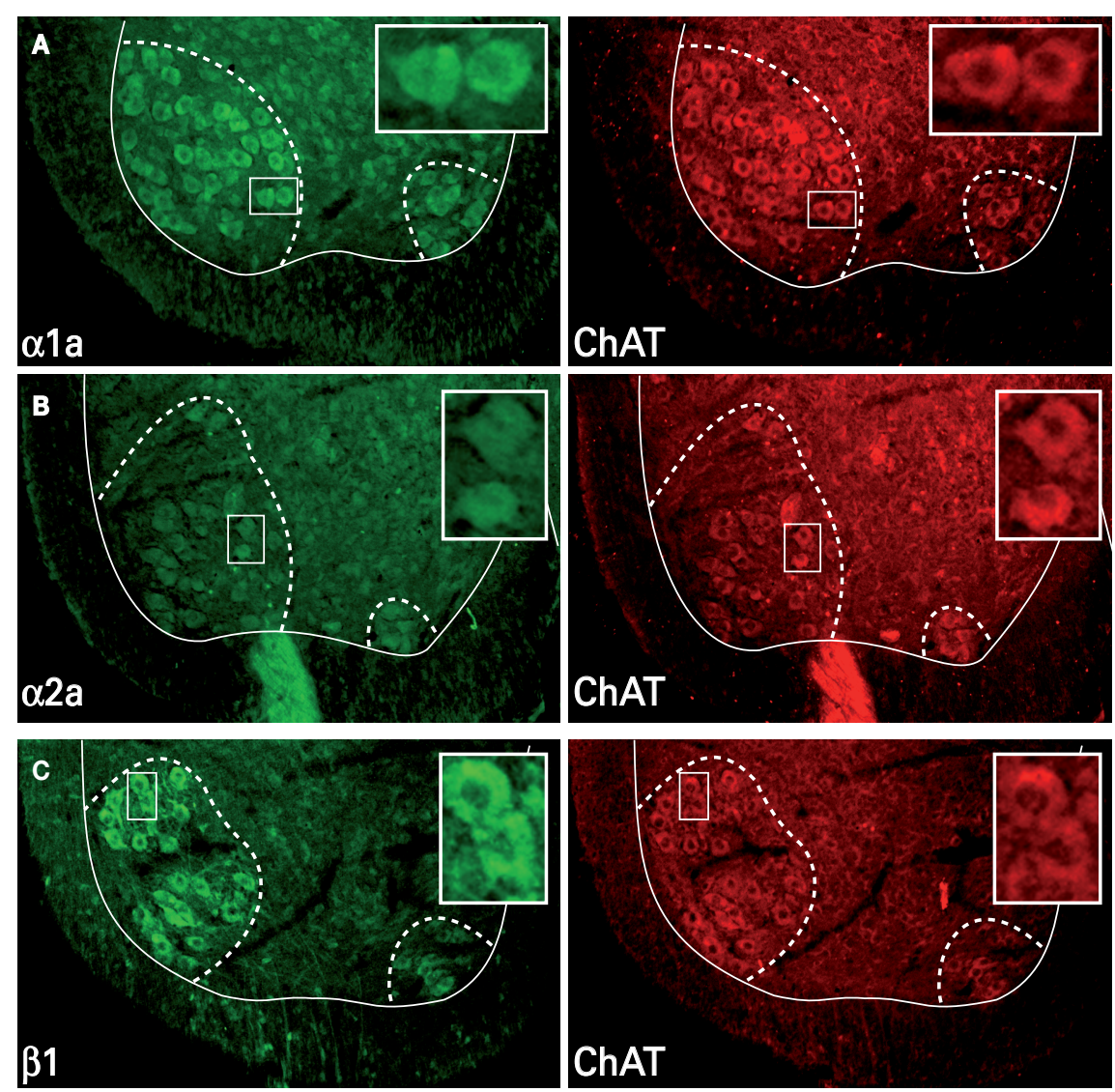
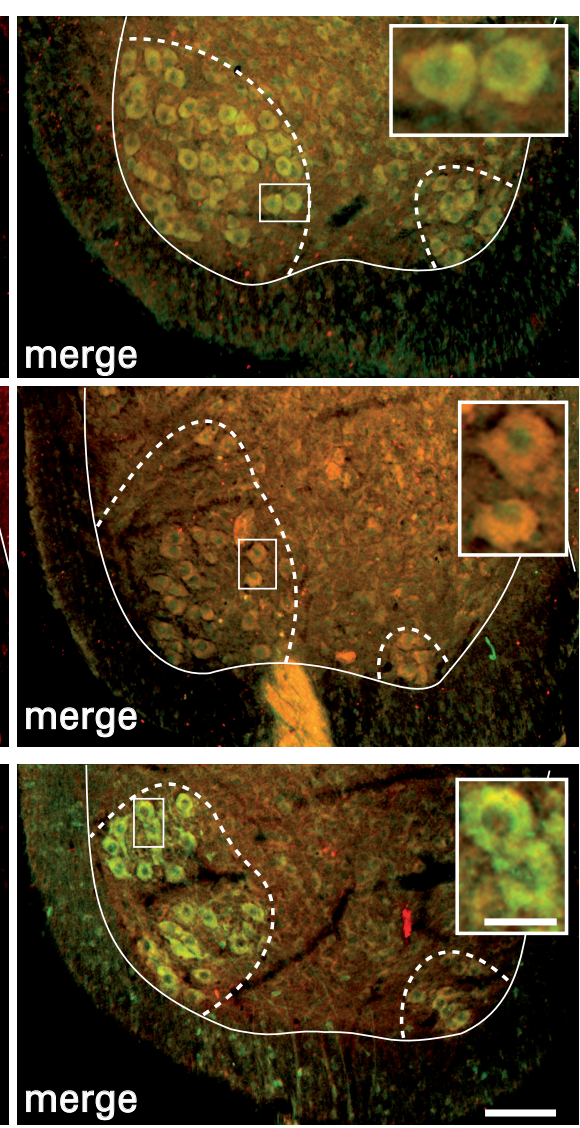

FIGURE 1 | Expression of adrenoreceptor subtypes in cholinergic neurons in transverse sections of the lumbar spinal cord. Double labeling of large neuronal cell bodies in lamina IX (dashed lines) for alpha 1a (A); alpha 2a (B); beta 1 (C) noradrenergic receptors (green) and choline acetyltransferase (ChAT, red). The merge panels show that a high proportion of cholinergic neurons in lamina IX are immunopositive for the three different noradrenergic receptors. Scale bars $100 \mu \mathrm{m}$. The area boxed in the different panels is shown at higher magnification in the insets (scale bar $30 \mu \mathrm{m}$ ). 
A

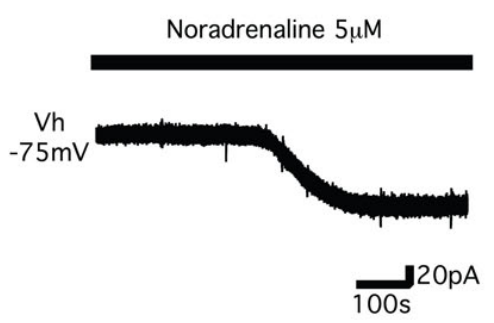

B3

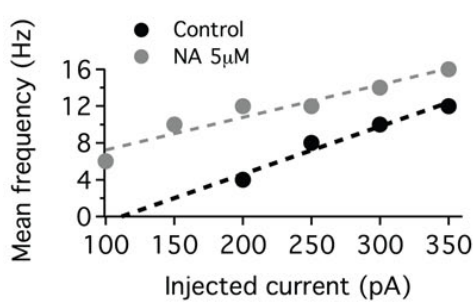

C1

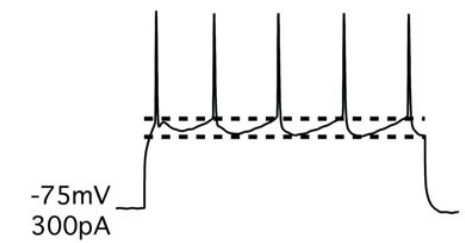

B1

Control

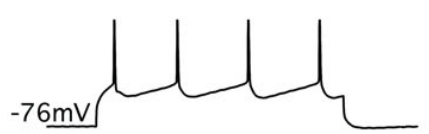

$300 \mathrm{pA}$

B2 Noradrenaline $5 \mu \mathrm{M}$

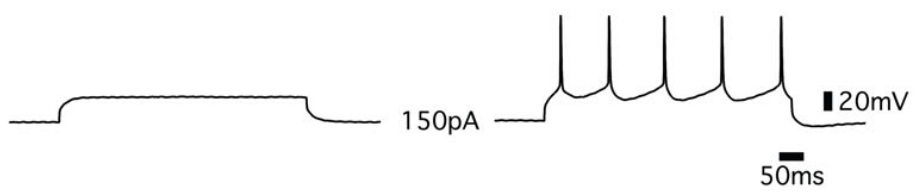

B4

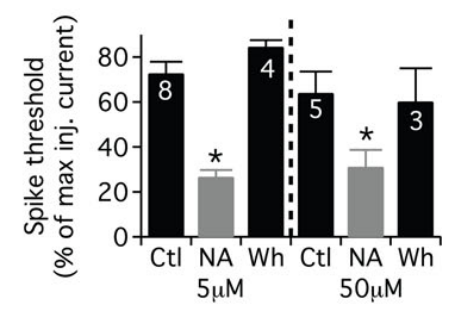

B5

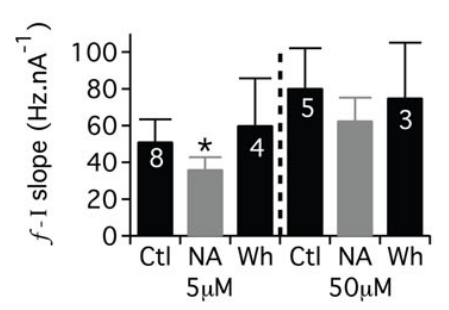

C2

NA $5 \mu \mathrm{M}(10 \mathrm{~Hz})$

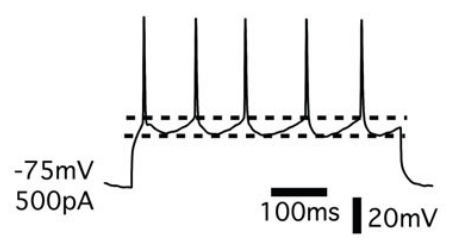

C3

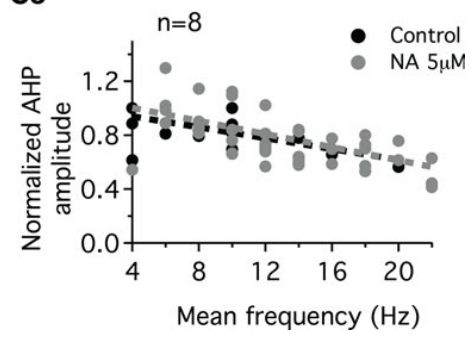

FIGURE 2 | Effects of noradrenaline (NA) on the membrane properties of the lumbar motoneurons. (A) Representative trace showing the NA-induced inward current in motoneurons held at $-75 \mathrm{mV}(\mathrm{Vh})$. (B) A representative cell recording showing that NA increases the excitability and the spike frequency (B1,B2) in response to depolarizing current pulses. (B3) Plot of the mean spike frequency as a function of the injected current from the cell shown in (B1,B2). (B4) The spike threshold computed as the percentage of the maximum injected current needed to evoke a spike during a series of depolarizing current steps in control conditions (Ctl), in the presence of NA and after a 30-min wash-out (Wh). (B5) Summary histograms of the slope of the frequency current ( $f-l$ ) relationship in control conditions (CtI), in the presence of NA and after a 30-min wash-out (Wh). (C) Representative traces of the spike AHP indicated by dashed lines in control (C1) and in the presence of NA (C2) at similar firing rates. Plot of normalized AHP amplitude as a function of the mean spiking frequency during a series of depolarizing steps in control conditions and in the presence of NA (C3)

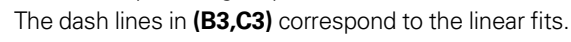

modifies the instantaneous frequency-current $(\mathrm{f}-\mathrm{I})$ relationships of motoneurons, we applied a series of depolarizing current steps before (Figure 2B1) and after (Figure 2B2) bath applying NA in cells held at their control resting membrane potential by injecting hyperpolarizing bias current. As shown in Figure 2B3 computed from the motoneuron presented in Figures 2B1,B2, NA increased the spike frequency and decreased the spike threshold of the motoneuron. To quantify the NA-induced changes in lumbar motoneuron excitability, the spike threshold was expressed as the percentage of the maximum injected current needed to trigger a spike during a series of depolarizing current steps in normal saline and in the presence of NA. Figure 2B4 shows that both 5 and $50 \mu \mathrm{M}$ NA significantly and reversibly decreased spike threshold compared to control conditions. We then computed the slope of the f-I relationship for all motoneurons tested. The average $f-I$ slope was significantly and reversibly decreased in the presence of $5 \mu \mathrm{M}$ NA (Figure 2B5, see also Figure 2B3) and tended to be reduced when $50 \mu \mathrm{M}$ NA was added to the saline (Figure 2B5).
Spike afterhyperpolarization (AHP) plays a fundamental role in controlling the firing frequency and patterning of activity in motoneurons and is consequently targeted by almost all neuromodulatory systems (for examples see Bayliss et al., 1995; Chevallier et al., 2006; Han et al., 2007). For each motoneuron, the relationship between the AHP amplitude and the firing frequency was well fitted using linear equation (mean $r=0.98 \pm 0.01, n=8$ ) in control conditions. We sought whether NA modifies this relationship. As seen in the representative motoneuron recordings of Figures $2 \mathrm{C1}, \mathrm{C} 2$, at similar firing rate values, the AHP amplitude was not modified by the addition of NA (Figure 2C2) compared to control conditions (Figure 2C1). In the presence of NA, the relationship between the AHP amplitude and the firing rate was well fitted by linear equation (mean $r=0.97 \pm 0.01$ ). The pooled data plot of Figure 2C3 shows the AHP amplitude, normalized in individual motoneuron tested by the maximum AHP amplitude computed in control conditions, and expressed as a function of the mean spike frequency measured during a series of depolarizing steps. The linear fit equation was 
Table 1 | Mean current induced by the bath-application of the different noradrenergic compounds recorded from motoneurones held at $-75 \mathrm{mV}$ and mean input resistance in control conditions and in the presence of the drugs.

\begin{tabular}{|c|c|c|c|c|}
\hline & & \multirow[t]{2}{*}{ Drug-induced-current (pA) } & \multicolumn{2}{|c|}{ Input resistance $(\mathrm{M} \Omega)$} \\
\hline & & & Control & Drug \\
\hline & $\mathrm{NA} 50 \mu \mathrm{M}$ & $-81 \pm 22, n=6$ & $197.8 \pm 33$ & $243.3 \pm 22.4^{*}$ \\
\hline \multirow[t]{2}{*}{$\alpha_{1}$} & Methoxamine $80 \mu \mathrm{M}$ & $-96.2 \pm 22, n=8$ & $141.4 \pm 33$ & $178.2 \pm 41^{*}$ \\
\hline & Prazosin $50 \mu \mathrm{M}$ & $-4.3 \pm 4, n=6$ & $161.6 \pm 19$ & $156.1 \pm 26$ \\
\hline \multirow[t]{3}{*}{$\alpha_{2}$} & Clonidine $1 \mathrm{mM}$ & $12 \pm 4, n=7$ & $114.5 \pm 16$ & $130.9 \pm 18$ \\
\hline & Yohimbine $50 \mu \mathrm{M}$ & $-5.8 \pm 5, n=6$ & $141.9 \pm 23$ & $156 \pm 23$ \\
\hline & Yohimbine + clonidine & $7.2 \pm 5, n=6$ & $156 \pm 23$ & $164 \pm 22$ \\
\hline$\beta$ & Isoproterenol $50 \mu \mathrm{M}$ & $-18.8 \pm 5, n=8$ & $187.9 \pm 50$ & $210.7 \pm 60$ \\
\hline
\end{tabular}

Negative current: inward current and positive current: outward current. Data \pm SEM

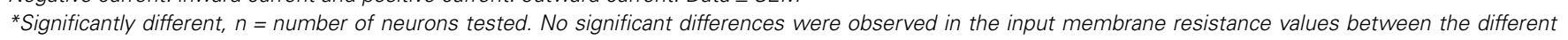
motoneuronal pools in control conditions (Kruskal-Wallis test, $p=0.2$ ).

$-0.024 \mathrm{x}+1$ in control condition and $-0.02 \mathrm{x}+1$ with $5 \mu \mathrm{M}$ NA, $n=8$ and $-0.018 \mathrm{x}+1$ in control condition and $-0.017 \mathrm{x}+0.9$, $n=5$ with $50 \mu \mathrm{M}$ NA in the bath (data not shown). The slopes and the intercepts of these linear fits were not significantly different between control condition and in the presence of NA. To validate this method, we applied short depolarizing pulses ( $4 \mathrm{~ms}$ ) to evoke a single spike followed by an AHP in the absence or presence of NA. The amplitude and the duration of the AHP were not significantly changed after administration of NA $(4.6 \pm 0.9 \mathrm{mV}$ and $200 \pm 20 \mathrm{~ms}$, respectively, in control conditions and $4.8 \pm 0.9 \mathrm{mV}$ and $231 \pm 22 \mathrm{~ms}$ in NA; $n=6$ ). Altogether these results indicate that NA modified the $\mathrm{f}-\mathrm{I}$ relationship without affecting the AHP amplitude in the lumbar motoneurons of neonatal rats.

Lumbar motoneurons were previously shown to possess both the hyperpolarization-activated mixed-cation current $\mathrm{I}_{\mathrm{H}}$ and the inwardly rectifying $\mathrm{K}^{+}$current $\mathrm{K}_{\mathrm{IR}}$ (Takahashi, 1990; Kjaerulff and Kiehn, 2001). Thus, we analyzed the effects of NA on $I_{H}$ and $\mathrm{K}_{\mathrm{IR}}$ currents. Membrane potential was stepped from a holding potential of -75 to $-155 \mathrm{mV}$ (10 steps, $8 \mathrm{mV}$ increment, $500 \mathrm{~ms}$ step duration) before (Figure 3A1) and during application of NA (Figure 3A2). The instantaneous current was measured immediately after the capacitive transient (filled circle in Figures 3A1,A2) and the steady-state current at the end of the $500 \mathrm{~ms}$ hyperpolarizing pulse (open circle in Figures 3A1,A2). The difference (filled triangle in Figure 3A3) between the steady state current and the instantaneous current was defined as $\mathrm{I}_{\mathrm{H}}$ on the basis of its voltage dependence (Bayliss et al., 1994; Kjaerulff and Kiehn, 2001). Lumbar motoneurons exhibited a small inward current activated by hyperpolarization in control conditions (Figure 3A1). Fifty micromolar NA did not alter the current-voltage (I-V) curve measured from series of hyperpolarizing pulses (Figures 3A2,A3). The amplitude of $\mathrm{I}_{\mathrm{H}}$ measured at $-150 \mathrm{mV}(n=13$ motoneurons) was not significantly different between control conditions and in 5 or $50 \mu \mathrm{M}$ NA $(-34.4 \pm 13$ and $-18.7 \pm 24 \mathrm{pA}$, respectively). The modulation of $\mathrm{K}_{\mathrm{IR}}$ by NA was also studied using voltage ramps from -55 to $-135 \mathrm{mV}$ (Figure 3B1). The control I-V relationship was subtracted from the NA I-V relationship to obtain the I-V relationship of the NA-suppressed current. Superfusion of NA $(5 \mu \mathrm{M})$ inhibited an outward current at membrane potentials near rest that became inward around $-110 \mathrm{mV}$ (Figure 3B2). The mean reversal potential measured in $5 \mu \mathrm{M}\left(E_{\text {rev }},-104.4 \pm 1.4 \mathrm{mV}\right.$, $n=10)$ or $50 \mu \mathrm{M}(-97.6 \pm 3.1 \mathrm{mV}, n=6) \mathrm{NA}$ was close to the $\mathrm{K}^{+}$ equilibrium potential $(-99 \mathrm{mV})$ calculated with the Nernst equation. The chord conductance $(\mathrm{G})$ of the current (I) measured at $-80 \mathrm{mV}\left(V_{\mathrm{m}}\right)$ using the formula $G=I /\left(V_{\mathrm{m}}-E_{\mathrm{rev}}\right)$ as $3.5 \pm 0.7 \mathrm{nS}$ in $5 \mu \mathrm{M} \mathrm{NA}(n=10)$ and $2.3 \pm 1 \mathrm{nS}$ in $50 \mu \mathrm{M} \mathrm{NA}(n=6)$.

As the voltage ramps protocol may activate both $\mathrm{I}_{\mathrm{H}}$ and $\mathrm{K}_{\mathrm{IR}}$ currents, we tested the effects of NA in the presence of ZD7288 a blocker of $I_{H}$ current. Since inwardly rectifying currents conduct more inward current (at membrane potentials hyperpolarized relative to the reversal potential, $E_{\text {rev }}$ ) than outward current (at membrane potentials depolarized relative to $E_{\text {rev }}$ ), we examined the chord conductance of the suppressed currents. The chord conductances were obtained by subtracting the instantaneous I-V curves obtained in the presence of the different pharmacological compounds from the curves obtained in control, at membrane potentials equidistant from the reversal potential at $V_{\mathrm{m}}=E_{\text {rev }}-25\left(E_{\text {rev }}-25\right.$; for inward current) versus $V_{\mathrm{m}}=E_{\mathrm{rev}}+25\left(E_{\mathrm{rev}}+25\right.$; for outward current; see Figure 3D2) (Bertrand et al., 2003b).

In motoneurons in which $\mathrm{I}_{\mathrm{H}}$ current was present in control conditions during series of hyperpolarizing pulses (Figures 3C1,C2), $20 \mu \mathrm{MZD} 7288$ abolished a slow inward rectification (Figures 3C3,G) and unmasked a fast inward rectification (Figures 3C3,C4). The application of NA in the presence of ZD7288 reduced the instantaneous current over the entire voltage range tested (Figures 3D1,D2). It is noticeable that as previously shown for serotonin (Kjaerulff and Kiehn, 2001) the reduction was stronger for the outward part of the current (Figures 3D2,G). $\mathrm{K}_{\mathrm{IR}}$ channels present the characteristic to 


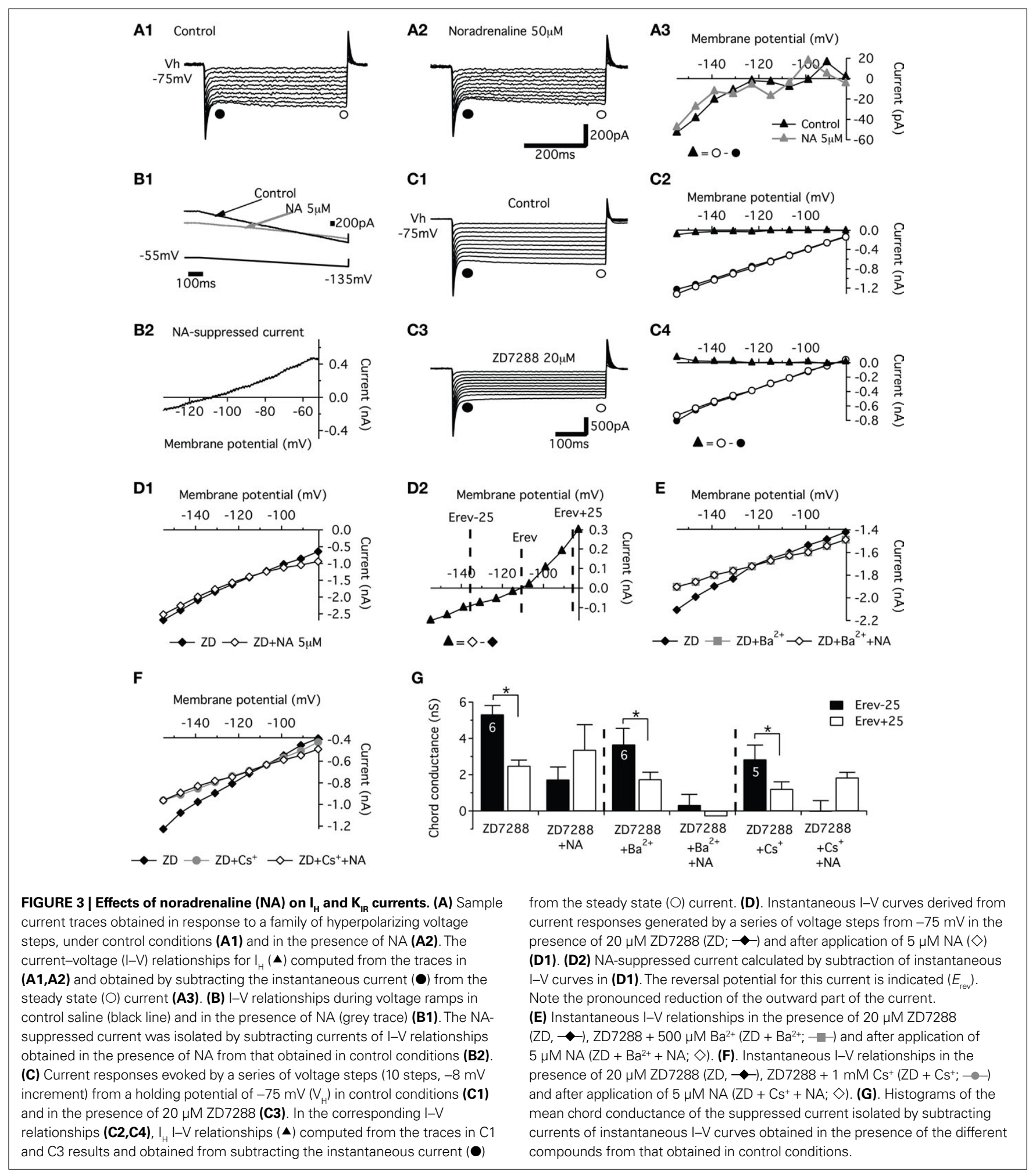

be blocked in a voltage-independent manner by external $\mathrm{Ba}^{2+}$ and in a voltage-dependent manner, with no effect on outward current, by external $\mathrm{Cs}^{+}$(Sodickson and Bean, 1996; Bertrand et al., 2003a). To assess whether NA modulates such a $\mathrm{K}_{\mathrm{IR}}$ current in lumbar motoneurons, the effects of NA were then investigated in the presence of ZD7288 in combination with $\mathrm{Ba}^{2+}$ or $\mathrm{Cs}^{+}$. Addition of $\mathrm{Ba}^{2+}(500 \mu \mathrm{M})$ during voltage steps series in the presence of ZD7288 revealed a block of both outward and inward part of the instantaneous I-V curves (Figure 3E). The chord conductances of the $\mathrm{Ba}^{2+}$-sensitive current were characteristic of an inwardly rectifying 
current with significant different values measured at $E_{\text {rev }}-25$ and $E_{\text {rev }}+25$ (Figure 3G). When NA was added to the ZD72288 $+\mathrm{Ba}^{2+}$ containing saline, no further effects were observed on the instantaneous I-V curves (Figures 3E,G). As shown in Figures 3F,G, $\mathrm{Cs}^{+}$strongly reduced the inward component of the endogenous current and elicited a smaller decrease on its outward portion. In contrast to the $\mathrm{Ba}^{2+}$ block that occluded the NA effects with no voltage dependency, NA still decreased the outward portion of the $\mathrm{Cs}^{+}$-insensitive current but failed to affect its inward component in the presence of $\mathrm{Cs}^{+}$and ZD7288 (Figures 3F,G). In summary, this series of experiments indicate that $\mathrm{K}_{\mathrm{IR}}$ current is under NAergic neuromodulatory control in lumbar motoneurons. All effects of NA were fully reversible after a wash-out period of at least $30 \mathrm{~min}$ (data not shown).

To assess the role of the three classes of adrenoreceptors in the modulation of the motoneuronal membrane properties, the same paradigms were performed in the presence of the three different agonists. Sqalli-Houssaini and Cazalets (2000) previously showed using extracellular recordings that $50 \mu \mathrm{M}$ methoxamine, $100 \mu \mathrm{M}$ isoproterenol and $100 \mu \mathrm{M}$ clonidine slow down the locomotor rhythm. Based on these results, we determined the concentration of each agonist that consistently and reproducibly elicited changes in motoneuron membrane potential. We found that $80 \mu \mathrm{M}$ methoxamine and $50 \mu \mathrm{M}$ isoproterenol triggered an inward current in motoneurons held at $-75 \mathrm{mV}$ (Figure $4 \mathrm{~A}$ and Table 1 ). In two neurons (data not shown), we observed that 100 or $500 \mu \mathrm{M}$ clonidine caused no detectable variations in the motoneuron membrane potential while $1 \mathrm{mM}$ clonidine induced a consistent outward current (Figure 4A and Table 1). Despite the fact that their effects on the membrane potential of the motoneurons differ, the three agonists increased the membrane input resistance of lumbar motoneurons (Table 1). These changes in membrane input resistance were significantly different in the presence of methoxamine while they only showed a tendency to be increased in the presence of clonidine or isoproterenol (see Table 1). We then tested the changes induced by methoxamine (Figure 4B1), clonidine (Figure 4B2) and isoproterenol (Figure 4B3) on the motoneuron excitability. All three compounds reproduced the NA action, i.e., increased the firing frequency and decreased the spike threshold of lumbar motoneurons (Figures 4B1-B3). All three NAergic agonists increased the excitability of all motoneurons tested by significantly reducing their spike threshold (Figure $4 \mathrm{C1}$ ). The slope of the $\mathrm{f}-\mathrm{I}$ relationship computed during a series of depolarizing steps was significantly decreased in the presence of isoproterenol and also tended to decline in the presence of methoxamine and clonidine (Figure 4C2). In the presence of the different NAergic agonists, the correlation coefficient of the linear fit of the relationship between the AHP amplitude and the firing rate in each neuron was not significantly different compared to control conditions $(r=0.98 \pm 0.1$ in control and $0.97 \pm 0.1, n=22$ in the presence of the agonists). When the normalized AHP amplitude was expressed as a function of the mean frequency, the slope and the intercepts of the linear fit of this relationship were not significantly modified in the presence of clonidine for the population of motoneurons tested (Figure 4C3; control $-0.025 \mathrm{x}+1$; clonidine $-0.025 \mathrm{x}+1 n=7$ ), or of isoproterenol (data not shown, control $-0.018 \mathrm{x}+1$; isoprotere nol- $0.022 \mathrm{x}+1, n=7$ ) or of methoxamine (data not shown, con- trol $-0.03 x+1.2$; methoxamine $-0.033 x+1.2, n=8)$. As illustrated in the presence of isoproterenol (Figure 4D), none of the three adrenoreceptors agonists altered the $\mathrm{I}-\mathrm{V}$ curve obtained from membrane voltage steps ( 10 steps, $8 \mathrm{mV}$ increment). The amplitude of the $\mathrm{I}_{\mathrm{H}}$ current measured at $-150 \mathrm{mV}$ was $-17 \pm 4 \mathrm{pA}$ in control, $-21 \pm 10 \mathrm{pA} n=7$ with isoproterenol; $-18.9 \pm 13$ in control, $-10.2 \pm 7 \mathrm{pA} n=8$ with methoxamine and $-26.3 \pm 16 \mathrm{pA}$ in control and $-24.5 \pm 5 \mathrm{pA} n=7$ with clonidine. In contrast, voltage ramps revealed that methoxamine and clonidine suppressed a current with an I-V curve computed by the subtraction of I-V relationships obtained in control condition and in the presence of one of the agonist (Figure 4E, example for methoxamine). In the presence of methoxamine or clonidine, the mean $E_{\text {rev }}$ of the suppressed current was $-101 \pm 2$ and $-94 \pm 2 \mathrm{mV}$ and the mean chord conductance measured at $-80 \mathrm{mV}$ was $2.7 \pm 1 \mathrm{nS}, n=8$ and $2.2 \pm 0.5 \mathrm{nS}, n=7$, respectively. Interestingly, we found that isoproterenol had a small inhibitory effect on the current expressed during voltage ramp in $50 \%$ of the motoneurons tested $\left(E_{\text {rev }}=-96 \pm 2 \mathrm{mV}\right.$ and chord conductance at $-80 \mathrm{mV}=1.1 \pm 0.4 \mathrm{nS}, n=4)$ and failed to affect it in the remaining $50 \%$ ( $n=4$; data not shown). This depressing effect of the different NAergic agonists on inward rectifying currents was still observed in the presence of the $\mathrm{I}_{\mathrm{H}}$ blocker ZD7288 ( $n=2$ with methoxamine, $n=2$ with clonidine and $n=1$ with isoproterenol; data not shown).

We then checked the specificity of the NAergic agonists by using specific antagonists. In a first step, we investigated whether prazosin $\left(\alpha_{1}\right.$ antagonist), yohimbine ( $\alpha_{2}$ antagonist) and propranolol ( $\beta$ antagonist) induced changes in the membrane properties targeted by the NAergic agonists in lumbar motoneurons. None of these antagonists, which were first bath-applied alone to the in vitro spinal cord, triggered significant inward or outward currents in motoneurons held at $-75 \mathrm{mV}$ (Figure 5A and Table 1) and caused no significant changes in motoneuron input membrane resistance (Table 1). Motoneuron excitability as well as the slopes of the $\mathrm{f}-\mathrm{I}$ relationship were also not altered by the antagonists (Figure 5B middle panels and 5C1-2). Prazosin (Figure 5D1) and yohimbine (data not shown) did not change the I-V relationships during voltage ramps from -55 to $-135 \mathrm{mV}$. In the presence of prazosin or yohimbine (dashed bars in Figure 5D2), the mean chord conductance of the current, measured at $-80 \mathrm{mV}$ and computed by the subtraction of $\mathrm{I}-\mathrm{V}$ relationships obtained in normal saline and in the presence of each antagonist, was small or even non-existent. The chord conductance of the current modulated by prazosin or yohimbine was significantly smaller than the methoxamine or clonidine-suppressed current reported above (open bars in Figures 5D2 and 4E). In the presence of propranolol, a small inhibitory effect on the I-V relationship was observed during voltage ramps (data not shown; Figure 5D2).

In a second step, we tested whether the antagonists abolished the actions of their respective agonists. As shown in Figure 5A and in Table 1, methoxamine and isoproterenol, when added to a prazosin or propranolol-containing medium, respectively, failed to induce any detectable inward current and a significant modification of the membrane input resistance. In the presence of yohimbine, clonidine still induced an outward current in motoneurons (Figure 5A2) but with an intensity that was almost 50\% less than in control condition (Table 1). This reduced outward current was not 


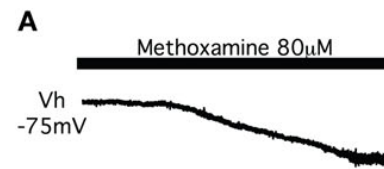

B1 Control<smiles>C#CC(C)CCCCC(=C)CCC(=C)CC</smiles><smiles></smiles>

C1

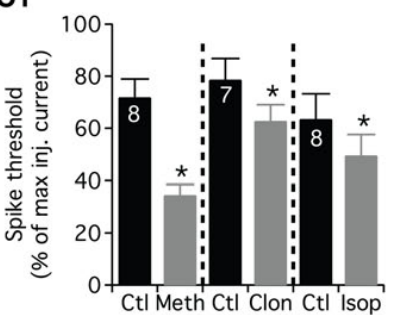

D1 Control

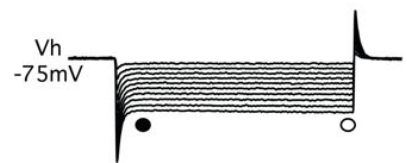

E1

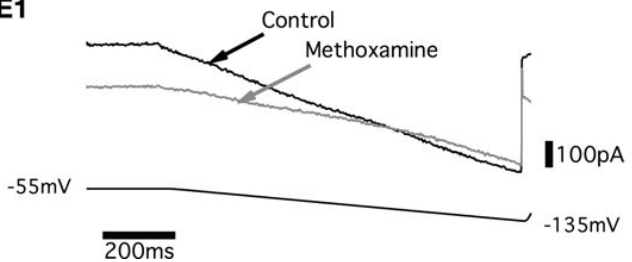

C2

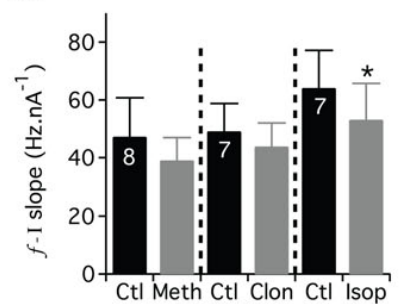

D2 Isoproterenol

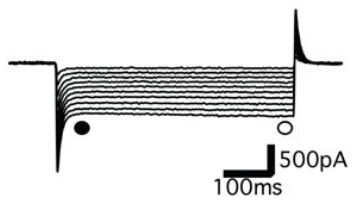

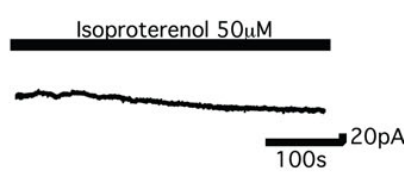

B3 Control Isoproterenol
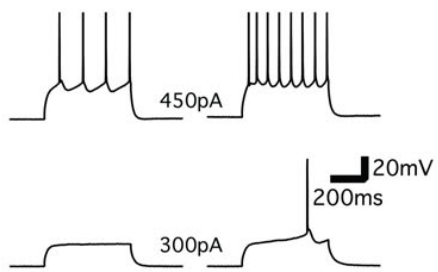

C3

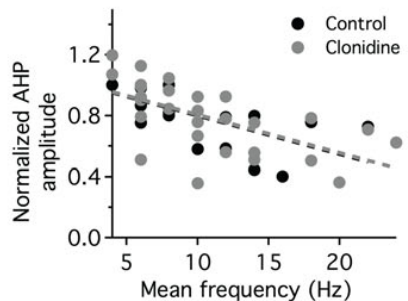

D3

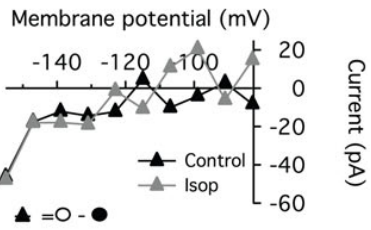

E2 Methox-suppressed current

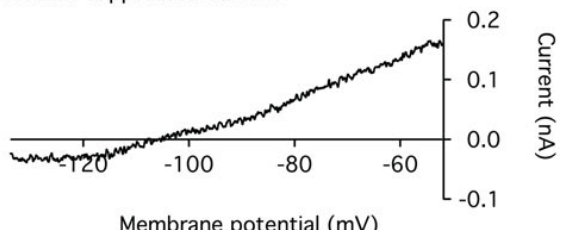

FIGURE 4 | Effects of the adrenoreceptor agonists on the membrane properties of the lumbar motoneurons. (A) Representative traces of the effects of methoxamine, clonidine and isoproterenol on the membrane potential of motoneurons held at $-75 \mathrm{mV}(\mathrm{Vh})$. (B) Representative traces of both the spike frequency and the threshold for spike generation during depolarizing current pulses (current value between the traces) in the absence and presence of methoxamine (B1), clonidine (B2) and isoproterenol (B3). (C,C1) Summary histograms of the spike threshold computed as the percentage of the maximum injected current needed to evoke spiking in the presence of methoxamine (Meth), clonidine (Clo) and isoproterenol (Iso) compared to control condition (Ctl). (C2) Summary histograms of the slopes of the frequency current $(f-l)$ relationship in the absence (filled bars) or presence of the noradrenergic agonists (grey bars). (C3) Plot of the normalized AHP amplitude as a function of mean spiking frequency during series of depolarizing steps in the absence or presence of clonidine. The dashed lines correspond to the linear fits (D). Sample current traces obtained in response to a family of hyperpolarizing voltage steps (first step -155 mV, $8 \mathrm{mV}$ increment) under control conditions and in the presence of isoproterenol (D1). The current-voltage (I-V) relationships ( $\mathbf{\Delta})$ computed from the traces in D1 results from subtracting the instantaneous ( from the steady state (O) current (D2). (E) I-V relationships obtained during voltage ramps in control saline (black trace) and in the presence of methoxamine (grey trace) (E1). The methoxamine-suppressed current was isolated by subtracting currents of $\mathrm{I}-\mathrm{V}$ relationship in the presence of the agonist from that in control condition (E2). associated with significant changes in the membrane input resistance (Table 1). When co-applied with their corresponding antagonists, methoxamine (Figure 5B1), clonidine (Figure 5B2) or isoproterenol (Figure 5B3) no longer caused an increase in motoneuron excitability. As evident in the summary plot in Figure 5C1, spike threshold was not significantly altered by the different antagonist- agonist combinations. The significant change in the $\mathrm{f}-\mathrm{I}$ relationship (Figure 4C2) was no longer observed when isoproterenol was bathapplied with propranolol (Figure 5C2). A similar effect on the f-I relationship was observed when methoxamine or clonidine were superfused in the presence of prazosin and yohimbine, respectively (Figure 5C2). Finally, methoxamine bath-applied with prazosin 


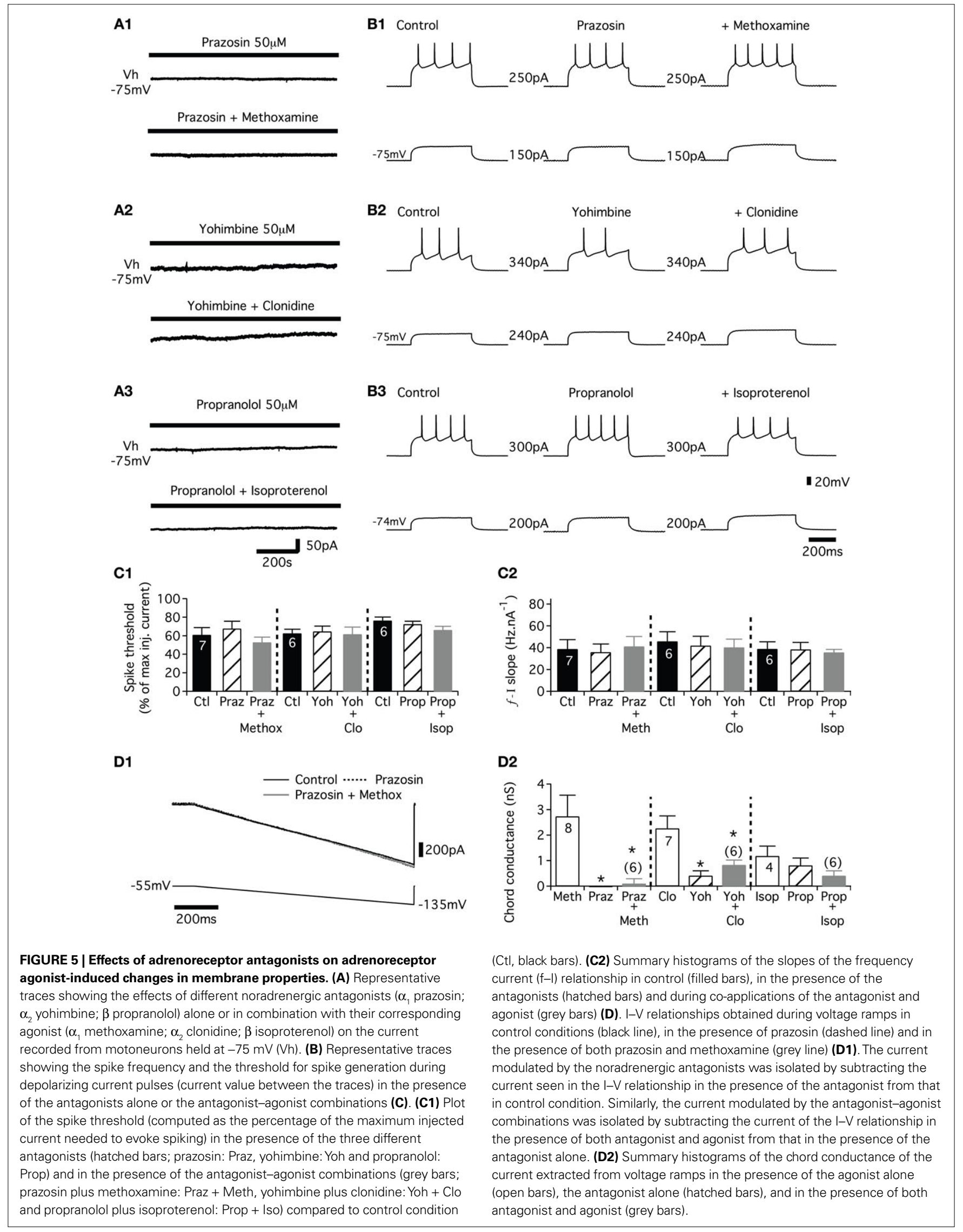


(Figure 5D1) or clonidine with yohimbine (data not shown) did not alter the current expressed during voltage ramp (Figure 5D2). The chord conductance of the current computed by subtraction of voltage ramps in the presence of the antagonist alone (hatched bars in Figure 5D2) and in the presence of both the antagonist and the agonist (grey bars in Figure 5D2) was significantly smaller than the one computed in the presence of methoxamine or clonidine alone (open bars in Figure 5D2). The chord conductance of the current observed during the co-application of isoproterenol and propranolol was further reduced, but not significantly, compared to the current suppression caused by isoproterenol alone (Figure 5D2).

Altogether these data suggest that (1) the membrane potential of the motoneurons could be differentially modulated depending on the type of adrenoreceptors activated (2) the NAergic system increased the excitability of the lumbar motoneurons partly via the inhibition a $\mathrm{K}_{\mathrm{IR}}$-like current and (3) the three different agonists, methoxamine, clonidine and isoproterenol, specifically activate $\alpha_{1}-$, $\alpha_{2}$ - and $\beta$-receptors, respectively, in lumbar motoneurons.

All the effects of the adrenoreceptor agonists described herein were not reversible after a 30-min period of wash-out with normal saline. When it was possible to obtain it, a partial wash was however observed when the wash-out period was extended to $1 \mathrm{~h}$ (data not shown).

\section{NORADRENERGIC MODULATION OF THE SYNAPTIC INPUTS RECEIVED BY THE LUMBAR MOTONEURONS}

In the isolated spinal cord preparation of the newborn rat, the T13L2 network sends a biphasic monosynaptic drive to the lumbar motoneurons consisting of alternating excitatory (glutamatergic) and inhibitory (glycinergic) synaptic inputs (Cazalets, 2000). Using the partitioned spinal cord preparation, experiments were conducted to analyze whether the NAergic system could modulate the synaptic inputs conveyed by the T13-L2 network to the L3L5 motoneurons. A Vaseline wall was then built at the L2 level to specifically activate the T13-L2 network independently from the caudal motoneurons. Fictive locomotion was induced by bathapplying a mixture of NMA/5HT on the thoracic and upper lumbar segments and recorded extracellularly from the L2 ventral root and intracellularly from lumbar motoneurons (Figure 6A). Strychnine $(1 \mu \mathrm{M})$ was added to the L3-L5 compartment to isolate the glutamatergic synaptic drive (Figure 6A1). In control conditions, the glutamatergic synaptic drive consists of small rhythmic depolarizations that could be in phase or out of phase with the extracellular ventral root recordings as an extensor and a flexor center are present in T13-L2 segments (Cazalets et al., 1995; Butt et al., 2002; Dougherty and Kiehn, 2009) (Figure 6B1 see also

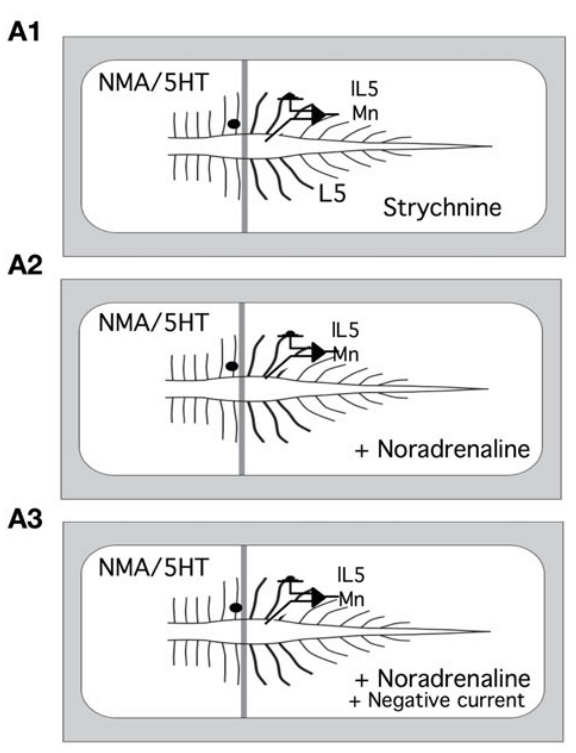

B4

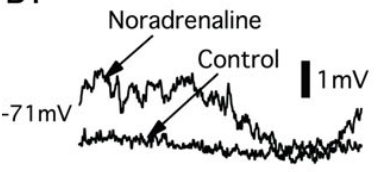

C

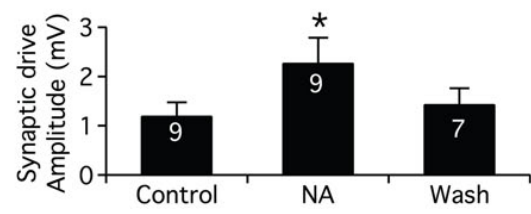

B1 IL2

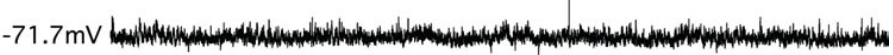

I $2 \mathrm{mV}$

\section{B2}

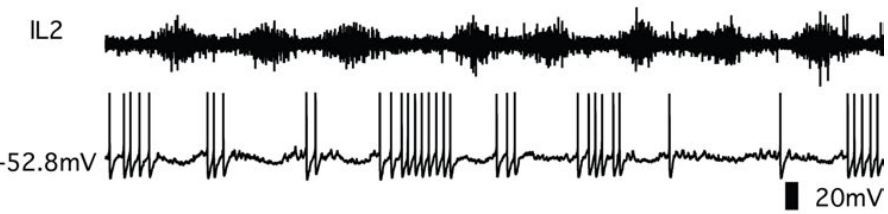

B3
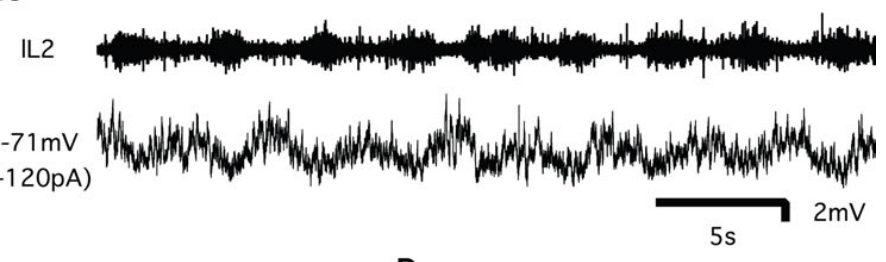

D

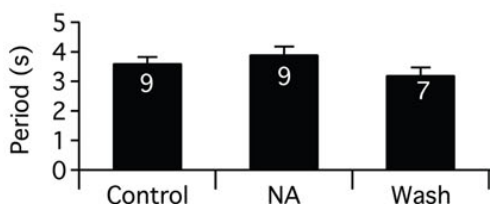

FIGURE 6 | Effects of NA on the glutamatergic synaptic drive.

(A) Schema of the experimental procedure. Vaseline wall (grey bar) was built at the L2 level. NMA/5HT was bath applied to the rostral compartment whereas strychnine alone (A1) or in combination with noradrenaline (NA) $(\mathbf{A 2}, \mathbf{A 3})$ was superfused onto the caudal compartment. (B) Representative traces recorded from a left L5 motoneuron (IL5) that was rhythmically depolarized out of phase with the IL2 ventral root activity (B1). In the presence of NA, the motoneuron was strongly depolarized and spiking activity was superposed on the depolarizing phases (B2). The injection of hyperpolarizing bias current (B3) revealed a strong amplification of the synaptic drive received by the motoneuron in the presence of NA. (B4) Mean synaptic drive computed from the traces in $(\mathbf{B 1} \mathbf{B} \mathbf{B})$. Summary plots of the mean synaptic drive amplitude (C) and of the rhythm period (D) in the presence or absence of NA. 
Figures 7B1,C1,D1). The addition of NA $(5 \mu \mathrm{M})$ to the L3-L5 compartment induced a strong depolarization of the recorded cells that reached the spike threshold generation in the majority of the cells tested (seven of nine neurons; mean membrane potential $-73.5 \pm 1 \mathrm{mV}$ in control and $-58.2 \pm 2 \mathrm{mV}$ in the presence of NA, $n=9$ ). The spiking activity could be restricted to the depolarizing phase of the locomotor drive as illustrated in Figure 6B2 (four neurons of seven) or sustained (three neurons of seven; data not shown). To analyze the variation of the excitatory synaptic drive induced by NA, hyperpolarizing bias currents were injected into the cells to return to their control membrane potential value (Figure 6B3). Figure 6B4 shows a representative trace of the mean synaptic drive (see Section "Materials and Methods") computed in control condition and in the presence of NA. NA strongly and reversibly enhanced the amplitude of the synaptic drive conveyed by the T13-L2 locomotor network to the caudal

A

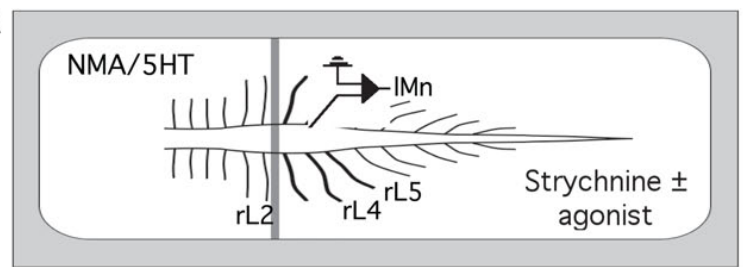

B1 Control

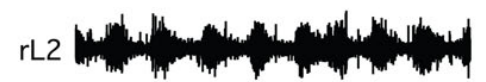

IL5 Mn

$-75 \mathrm{mV}$

\section{C1 Control}

IL2

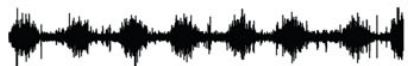

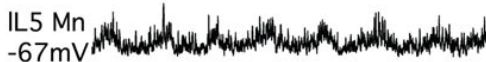

D1 Control

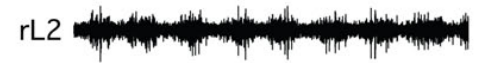

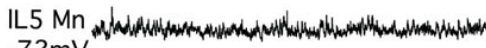
$-72 \mathrm{mV}$

$\mathbf{E}$

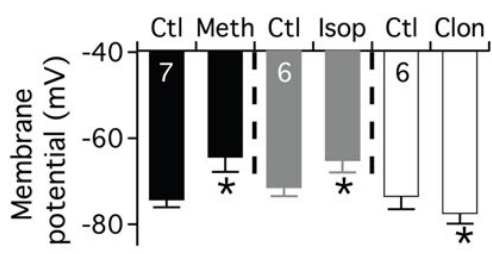

B2 Methoxamine L3/L5
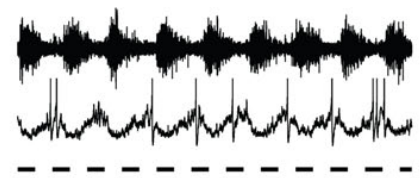

C2 Isoproterenol L3/L5
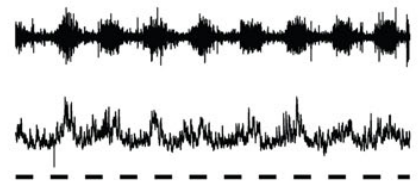

B3 Methoxamine L3/L5

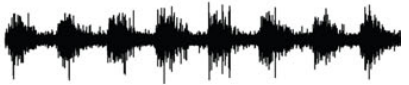

$(-120 p A)$

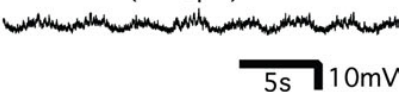

C3 Isoproterenol L3/L5

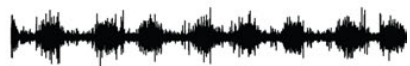

$(-10 p A)$

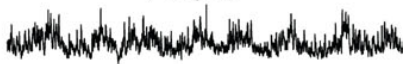

$5 \mathrm{~s} 5 \mathrm{mV}$

D2 Clonidine L3/L5

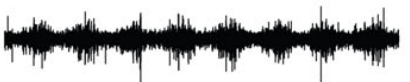

D3 Clonidine L3/L5

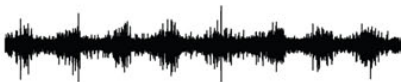

(38pA)

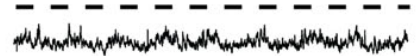

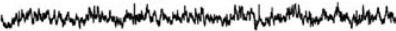

$\mathbf{F}$

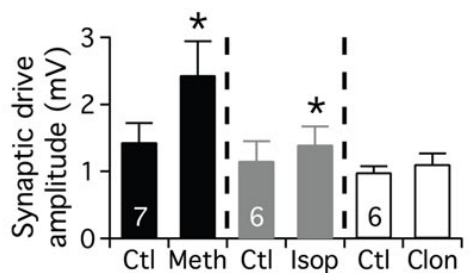

FIGURE 7 | Effects of the NAergic agonists on the glutamatergic synaptic drive. (A) Schema of the experimental procedure. NMA/5HT was added to the saline superfused on the rostral compartment to elicit fictive locomotion recorded extracellularly from the L2 ventral roots. Strychnine was bath applied alone or in combination with one of the agonist on the caudal compartment of the spinal cord and motoneurons were recorded in the left part of the cord.

Representative motoneurons recorded from the right or left $L 5$ segment $(r L 5$ or IL5) in control condition (B1,C1,D1) and in the presence of methoxamine (B2), isoproterenol (C2) or clonidine (D2). Hyperpolarizing (B3,C3) or depolarizing (D3) bias current (value in parenthesis) was injected into neurons to returned to their control membrane potential in the presence of the different noradrenergic agonists. The dash lines in (B2,C2,D2) correspond to the control membrane potential value of the neurons before the agonist application. Summary plot of the mean membrane potential (E), the mean synaptic drive amplitude (F) and the rhythm period $\mathbf{( G )}$ in the presence of methoxamine (black bars), isoproterenol (grey bars) and clonidine (white bars). 
lumbar motoneurons (Figure 6C). This enhancing action is not associated with any change in the period of the fictive locomotor rhythm (Figure 6D). When the NA concentration was raised to $50 \mu \mathrm{M}$ on the caudal lumbar segments, the motoneuronal membrane potential was very difficult to stabilize and to maintain at control value. Therefore accurate measurement of the synaptic drive could not be performed (data not shown).

Using the same protocol, we subsequently examined the effects of the three adrenoreceptor agonists on the excitatory synaptic drive received by the lumbar motoneurons (Figure 7A). In these experimental conditions, methoxamine bath-applied on the L3-L5 segments induced a significant depolarization of the motoneurons (Figure 7E) that reached the threshold for spike generation (compare Figures 7B1,B2). When motoneurons were held at their control membrane potential by injecting hyperpolarizing bias current (Figure 7B3), we observed a strong potentiation of the locomotor synaptic drive in the presence of the $\alpha_{1}$ agonist (Figures 7B3,F). When added to the L3-L5 compartment, the $\beta$ agonist, isoproterenol significantly depolarized the lumbar motoneurons (Figures 7C1,C2,E) and slightly but significantly enhanced the synaptic inputs received by the motoneurons during fictive locomotion (Figure 7C3). In contrast, clonidine elicited an hyperpolarization of the motoneurons (Figures 7D1,D2,E). When depolarizing bias current was injected into the cells to return to their control membrane potential value (Figure 7D3), no significant change of the synaptic drive was observed (Figure 7F). The modifications of the synaptic drive amplitude did not rely on an effect on the T13-L2 locomotor network as the period of the rhythm was not modified by the bath-application of the adrenoreceptor agonists on the caudal lumbar segments (Figure 7G).

\section{PRESYNAPTIC CONTROL OF THE GLUTAMATERGIC TRANSMISSION}

To determine whether the NAergic modulation of the excitatory synaptic drive described herein could partly rely on presynaptic mechanisms, we conducted mEPSCs recordings experiments from motoneurons. For this purpose, the motoneurons were synaptically isolated with tetrodotoxin (TTX; $0.5 \mu \mathrm{M}$ ) and the inhibitory synaptic inputs were blocked by adding $1 \mu \mathrm{M}$ strychnine (glycinergic antagonist) and $1 \mu \mathrm{M}$ gabazine (GABAergic antagonist) to the saline. mEPSCs were blocked by the NMDA and AMPA receptors antagonists AP5 and CNQX $(5 \mu \mathrm{M}, n=3$ data not shown) suggesting that they were due to the release of glutamate and the activation of ionotropic glutamate receptors. The control mean mEPSC amplitude was $6.3 \pm 0.3 \mathrm{pA}$ ( $n=26$ motoneurons). As shown in the representative traces in Figure 8A1, $5 \mu \mathrm{M}$ NA decreased mEPSC frequency and shifted the distribution of inter-event interval to the right $(p<0.05$, KS test; Figure 7A2). Figure 8A3 shows that for each individual neuron $(n=5)$, NA significantly decreased the mean mEPSC frequency. The mean mEPSC frequency was reduced from $5.3 \pm 1 \mathrm{~Hz}$ in control condition to $3.6 \pm 1 \mathrm{~Hz}$ in the presence of NA. The pooled data also showed that the mean mEPSC amplitude was significantly altered (Figure 8E). The same inhibitory effect on both mEPSC frequency and amplitude was observed using $50 \mu \mathrm{M}$ NA. The mean mEPSC frequency and amplitude were respectively $7.2 \pm 2 \mathrm{~Hz}$ and $6.4 \pm 0.5 \mathrm{pA}$ in normal saline and $5 \pm 1.4 \mathrm{~Hz}$ and $5.6 \pm 0.9 \mathrm{pA}(n=3$, data not shown $)$ in the presence of $50 \mu \mathrm{M}$
NA. Next, we analyzed the effects of the three NAergic agonists on mEPSCs. We observed that clonidine and isoproterenol mimicked the inhibitory action of NA when superfused on the spinal cord. The bath-application of clonidine (Figure 8B1) or isoproterenol (Figure 8C1) decreased the mEPSC occurrence and significantly shifted the distribution of inter-event interval to the right (Figures 8B2,C2). The mean mEPSC frequency was significantly decreased from $6.1 \pm 1 \mathrm{~Hz}$ in normal saline to $3.9 \pm 1 \mathrm{~Hz}(n=5)$ in the presence of clonidine and from $7.2 \pm 2$ to $5.3 \pm 1 \mathrm{~Hz}(n=5)$ in the presence of isoproterenol. We observed a significant decrease of the mEPSC amplitude with isoproterenol and a substantial but not significant reduction in the presence of clonidine (Figure 8E). In contrast, methoxamine elicited an increase in the frequency of mEPSCs (Figure 8D1) and significantly shifted the distribution of inter-event interval to the left (Figure 8D2). The mean mEPSC frequency was significantly increased from $4 \pm 0.7 \mathrm{~Hz}$ in control conditions to $5.2 \pm 0.5 \mathrm{~Hz}(n=5)$ in the presence of methoxamine (Figure 8D3) while the mean mEPSC amplitude was not significantly reduced (Figure 8E).

\section{DISCUSSION}

The present work provides the first detailed analysis of the spinal cellular targets of the NAergic pathways in the lumbar motor spinal cord and reveals a very complex neuromodulatory system.

\section{MODULATION OF INTRINSIC PROPERTIES}

Voltage clamp recordings from neurons with extended dendritic tree, as motoneurons, should be interpreted with caution. In this study, we compare control conditions to different pharmacological conditions. Although we undoubtedly did not clamp the whole dendritic tree of the motoneurons, we reported a strong inhibitory effect on the $\mathrm{K}_{\mathrm{IR}}$ current by the NAergic agents during voltage ramps or pulses. The quantification of this effect is certainly reduced due to sub-optimal voltage clamp conditions, but its occurrence remains. Although the NAergic agents differentially modulate the membrane potential of the motoneurons, they all increased their excitability and input membrane resistance and reduced a $\mathrm{K}_{\mathrm{IR}}-$ like conductance. These results are in agreement with previous studies showing that membrane depolarization associated with an input resistance increase underlie the NAergic-induced increase in hypoglossal and cervical motoneuron excitability (Kitazawa et al., 1985; Bayliss et al., 1997). Lumbar motoneurons, however, exhibit a specific NAergic neuromodulatory profile since AHP and $I_{H}$ current are not targeted by the NAergic system in these neurons. This contrasts with data obtained from hypoglossal motoneurons in which NA reduces the AHP amplitude (Parkis et al., 1995) and clonidine inhibits the $I_{H}$ current (Parkis and Berger, 1997). These differences between hypoglossal and lumbar locomotor motoneurons could result from distinct NAergic receptor sub-type expression and/or intracellular coupling (Rekling et al., 2000). The $\mathrm{K}_{\mathrm{IR}}$ channels contribute to the resting membrane potential and neuronal excitability and for these reasons, they constitute the main targets of numerous G-protein coupled receptors (see for examples Bertrand et al., 2003a,b; Derjean et al., 2003; Chevallier et al., 2008). In the neonatal rat spinal cord, it has been shown that serotonin as NA increases the motoneuron excitability partly via the inhibition of $\mathrm{K}_{\mathrm{IR}}$-like current (Kjaerulff 


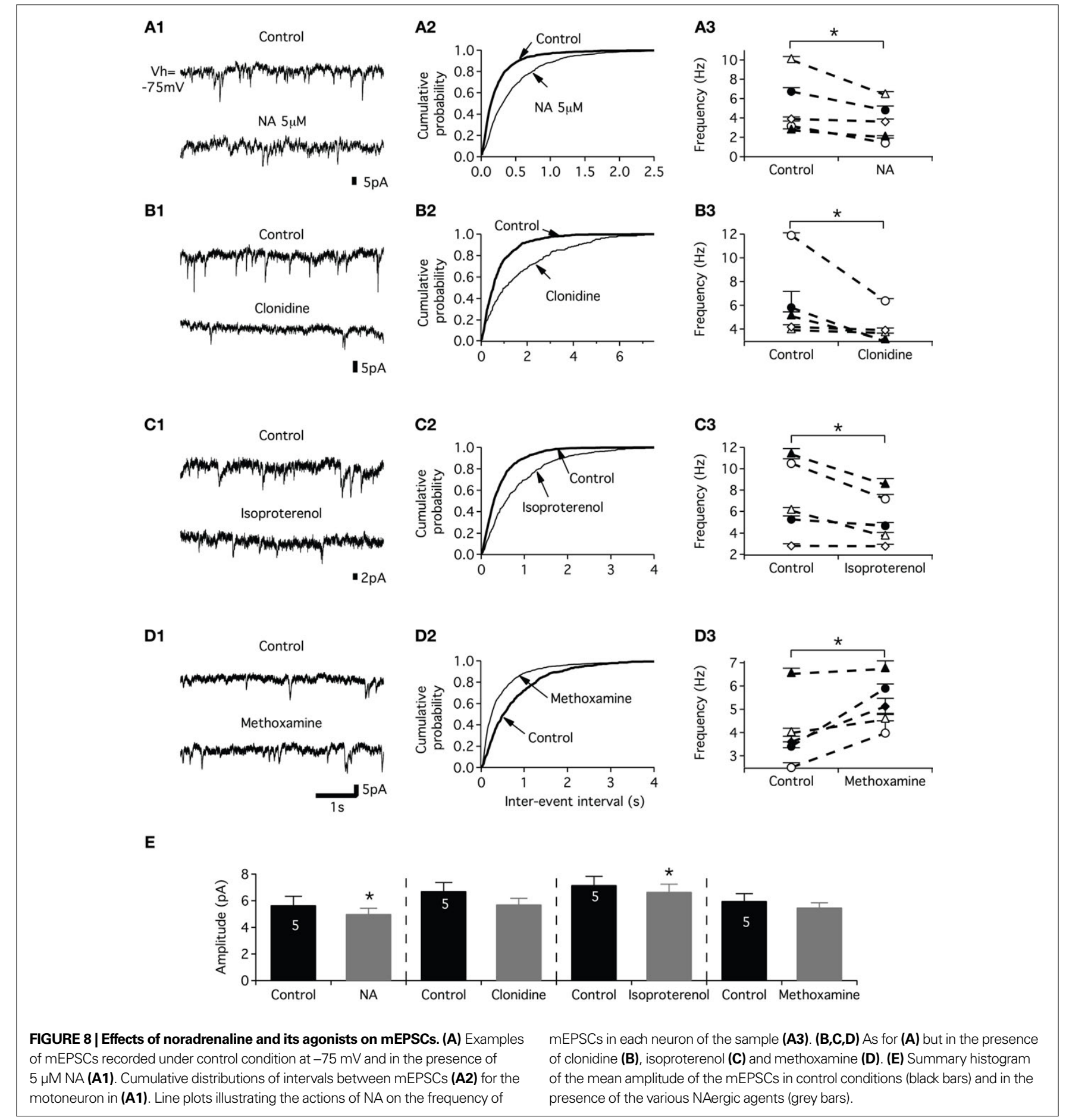

and Kiehn, 2001). A question now arises over how NA changes the slope of the f-I relationship without affecting the AHP amplitude. NA was reported to increase the excitability of spinal lumbar neurons by hyperpolarizing the spike threshold probably via a facilitation of the activation of $\mathrm{Na}^{+}$channels (Fedirchuk and Dai, 2004). Serotonin has been shown to facilitate an L-type calcium current in lumbar motoneurons (Li et al., 2007). The modulation of such calcium channels by NA could maybe also account for the changes observed in the f-I relationships slope.

\section{SPECIFICITY OF THE NAergic AGONISTS}

As previously mentioned, we investigated the threshold dose at which the agonist elicited significant changes in the motoneuron membrane potential. Using this criterion, some NAergic agonists were used at relatively high concentrations. We show, however, that the specific antagonists of NAergic receptors inhibit most of the effects of the NAergic agonists on the motoneuron membrane properties. This suggests that despite the high concentrations used, methoxamine, clonidine and isoproterenol specifically activate $\alpha_{1}$, 
$\alpha_{2}$ and $\beta$ receptors respectively. The need to use high clonidine concentration in newborn animals (see also Selvaratnam et al., 1998) maybe linked to the weak expression of the $\alpha_{2}$ receptors at this developmental stages and to the properties of the $\alpha_{2}$ receptor sub-types in motoneurons at birth.

\section{MODULATION OF SYNAPTIC TRANSMISSION}

The increase in the motor synaptic drive we reported herein could originate from a direct action on the motoneurons and/or a modulation of the glutamatergic transmission at the presynaptic level and/or on the rhythm-generating L3-L6 network of premotor interneurons (Kiehn, 2006). To discriminate among these various levels, we have used the partitioned spinal cord preparation and mEPSC recordings.

As previously mentioned, NA induces a slow non-locomotor rhythm and slows down the NMA-induced rhythm in the neonatal rat spinal cord preparation. In the neonatal rat spinal cord preparation, NA at the concentrations used in the present study, induces a slow non-locomotor rhythm and slows down the NMAor NMA/5HT-induced fictive locomotion (Kiehn et al., 1999; Sqalli-Houssaini and Cazalets, 2000). If we hypothesize that NA acts on the rhythm generating interneurons located in the L3-L6 segments, modifications of the locomotor period and/or locomotor pattern should have been observed in the intracellular and/or extracellular recordings. Such effects were no observed in this study. It has been also shown that the $\alpha_{1}$ agonist methoxamine speeds up the fictive locomotor rhythm without modifying the motor burst amplitude. On the contrary, the $\alpha_{2}$ and $\beta$ agonist receptors slow down the motor rhythm while simultaneously increasing the motor burst amplitude in the case of isoproterenol (Sqalli-Houssaini and Cazalets, 2000). If the potentiation of the T13-L2 synaptic drive solely relies on an activation of the L3-L6 CPG interneurons, we should have observed opposite effects on the locomotor period and on the synaptic drive amplitude during the superfusion of the $\alpha_{1}$ agonist versus the $\alpha_{2}$ and $\beta$ agonists. In the present study however, we observed that both methoxamine and isoproterenol increased the T13-L2 synaptic drive while clonidine failed to affect it. No effects were also reported on the locomotor period with any of the agonists. Although, these results suggest that the NAergic compounds directly control the T13-L2 descending glutamatergic inputs, the partial contribution of the L3-L6 interneurons to the increase of the T13-L2 synaptic drive could not, however, be completely excluded.

All NAergic agents except methoxamine decrease both the mEPSCs frequency and amplitude. In contrast, all NAergic compounds tested, except clonidine, enhance the excitatory synaptic drive arising from the T13-L2 network in L3-L5 motoneurons isolated with Vaseline wall. mEPSCs result from the glutamate release of all active synapses converging onto motoneurons. Using the partitioned spinal cord, we isolate the T13-L2 network synaptic drive from the other glutamatergic synapses impinging onto the motoneurons. Altogether our results then suggest that the glutamatergic inputs of the motoneurons, but certainly not all, are presynaptically inhibited via the activation of $\alpha_{2}$ and $\beta$ adrenoreceptors and potentiated via the activation of $\alpha_{1}$ adrenoreceptors, while the T13-L2 glutamatergic transmission is presynaptically enhanced by the activation of $\alpha_{1}$ adrenoreceptors. As the
T13-L2 segments are considered as the main rhythmogenic area of the lumbar cord (Cazalets, 2000), these results suggest that this locomotor-related excitatory synaptic drive could be specifically selected and favored by the NAergic pathways. These data further extend our knowledge on the modulation of the T13-L2 synaptic drive that was shown to be inhibited by the activation of presynaptic $\mathrm{GABA}_{\mathrm{B}}$ receptors and pre-and postsynaptic $\mathrm{GABA}_{\mathrm{A}}$ receptors (Bertrand and Cazalets, 1999).

\section{PHYSIOLOGICAL AND PATHOPHYSIOLOGICAL RELEVANCE}

Numerous studies have emphasized the role of the NAergic system in motor rhythms and segmental reflex modulations in animal models and humans (as for examples: Kitazawa et al., 1985; Chau et al., 1998a; Jankowska et al., 1998; Kiehn et al., 1999; Remy-Neris et al., 1999; Sqalli-Houssaini and Cazalets, 2000; Fischer et al., 2001; Barbeau and Norman, 2003; Gabbay and Lev-Tov, 2004; Machacek and Hochman, 2006; Barriere et al., 2008). Our data shed light on the complexity of the cellular bases of the NAergic modulation in the motor spinal networks. We have previously shown that NA controls the activity dependant plasticity expressed at sensorimotor synapses via the activation of GABAergic interneurons (Barriere et al., 2008). We demonstrated in the present study that depending on the adrenoreceptor expression and localization, the NAergic system could differentially and specifically modulate at both pre- and postsynaptic level the synaptic inputs and intrinsic properties of lumbar motoneurons.

After SCI, the excitatory supraspinal pathways controlling the spinal motor networks are damaged or lost. Functional rehabilitation strategies after SCI attempt, using various methods, to stimulate the sublesioned spinal cord. In spinal cats, $\alpha_{2}$ agonists are very efficient agents at initiating locomotion (Chau et al., $1998 b)$. In rodents models in contrast, $\alpha_{2}$ agonists appeared less potent than $\alpha_{1}$ agonists in inducing locomotor activity (SqalliHoussaini and Cazalets, 2000; Lapointe et al., 2008). In the present work, we provide part of the cellular bases accounting for the different potencies of clonidine and methoxamine in stimulating spinal motor networks in rat. We indeed showed that clonidine while it increases the motoneuron excitability globally inhibits the glutamatergic transmission received by the motoneurons in contrast to methoxamine that boosts it. It will be therefore very interesting to compare the cellular basis of the NAergic neuromodulation in intact and sublesioned lumbar motor networks and to assess the effect of methoxamine in spinal rodent models.

\section{ACKNOWLEDGMENTS}

The authors warmly thank Drs. Le Ray and Simmers for critical reading of the manuscript. This work was supported by grants from the conseil regional d'Aquitaine and by a CIHR-CNRS International Scientific Exchange Award. Jean-Claude Lacaille is supported by the Canadian Institutes of Health Research (operating grant MOP-10848), Fonds de la Recherche en Santé du Québec (FRSQ; Groupe de Recherche sur le système nerveux central), and the Canada Research Chair in Cellular and Molecular Neurophysiology. Grégory Barrière was supported by a postdoctoral fellowship from IRP. 


\section{REFERENCES}

Barbeau, H., and Norman, K. E. (2003). The effect of noradrenergic drugs on the recovery of walking after spinal cord injury. Spinal Cord 41, 137-143.

Barriere, G., Tartas, M., Cazalets, J. R., and Bertrand, S. S. (2008). Interplay between neuromodulator-induced switching of short-term plasticity at sensorimotor synapses in the neonatal rat spinal cord. J. Physiol. 586, 1903-1920.

Bayliss, D.A., Umemiya, M., and Berger, A. J. (1995). Inhibition of N- and P-type calcium currents and the after-hyperpolarization in rat motoneurones by serotonin. J. Physiol. 485(Pt. 3), 635-647.

Bayliss, D. A., Viana, F., Bellingham, M. C., and Berger, A. J. (1994). Characteristics and postnatal development of a hyperpolarization-activated inward current in rat hypoglossal motoneurons in vitro. J. Neurophysiol. 71, 119-128.

Bayliss, D. A., Viana, F., Talley, E. M., and Berger, A. J. (1997). Neuromodulation of hypoglossal motoneurons: cellular and developmental mechanisms. Respir. Physiol. 110, 139-150.

Bertrand, S., and Cazalets, J. R. (1999). Presynaptic GABAergic control of the locomotor drive in the isolated spinal cord of neonatal rats. Eur. J. Neurosci. 11, 583-592.

Bertrand, S., Morin, F., and Lacaille, J. C. (2003a). Different actions of gabapentin and baclofen in hippocampus from weaver mice. Hippocampus 13, 525-528.

Bertrand, S., Nouel, D., Morin, F., Nagy, F., and Lacaille, J.C. (2003b). Gabapentin actions on Kir3 currents and N-type $\mathrm{Ca} 2+$ channels via GABAB receptors in hippocampal pyramidal cells. Synapse 50, 95-109.

Butt, S. J., Lebret, J. M., and Kiehn, O. (2002). Organization of left-right coordination in the mammalian locomotor network. Brain Res. Brain Res. Rev. 40, 107-117.

Cazalets, J. R. (2000). Organization of the spinal locomotor network in neonatal rat. In Neurobiology of Spinal Cord Injury, R. Kalb and S. M. Stritmatter, eds (Totowa, NJ, Humana Press Inc.), pp. 89-111.

Cazalets, J. R., Borde, M., and Clarac, F. (1995). Localization and organization of the central pattern generator for hindlimb locomotion in newborn rat. J. Neurosci. 15, 4943-4951.

Chau, C., Barbeau, H., and Rossignol, S. (1998a). Early locomotor training with clonidine in spinal cats. $J$. Neurophysiol. 79, 392-409.

Chau, C., Barbeau, H., and Rossignol, S. (1998b). Effects of intrathecal alpha1-and alpha2-noradrenergic agonists and norepinephrine on locomotion in chronic spinal cats. $J$. Neurophysiol. 79, 2941-2963.

Chevallier, S., Nagy, F., and Cabelguen, J. M. (2006). Cholinergic control of excitability of spinal motoneurones in the salamander. J. Physiol. 570, 525-540.

Chevallier, S., Nagy, F., and Cabelguen, J. M. (2008). Muscarinic control of the excitability of hindlimb motoneurons in chronic spinal-transected salamanders. Eur. J. Neurosci. 28, 2243-2253.

Derjean, D., Bertrand, S., Le Masson, G., Landry, M., Morisset, V., and Nagy, F. (2003). Dynamic balance of metabotropic inputs causes dorsal horn neurons to switch functional states. Nat. Neurosci. 6, 274-281.

Dougherty, K. J., and Kiehn, O. (2009). Firing and cellular properties of V2a interneurons in the rodent spinal cord. J. Neurosci. 30, 24-37.

Fauser, C., Schimanski, S., and Wangemann, P. (2004). Localization of betal-adrenergic receptors in the cochlea and the vestibular labyrinth. J. Membr. Biol. 201, 25-32.

Fedirchuk, B., and Dai, Y. (2004). Monoamines increase the excitability of spinal neurones in the neonatal rat by hyperpolarizing the threshold for action potential production. J. Physiol. 557, 355-361.

Fischer, H., Merrywest, S. D., and Sillar, K. T. (2001). Adrenoreceptor-mediated modulation of the spinal locomotor pattern during swimming in Xenopus laevis tadpoles. Eur. J. Neurosci. 13, 977-986.

Forssberg, H., and Grillner, S. (1973). The locomotion of the acute spinal cat injected with clonidine i.v. Brain Res. 50, 184-186.

Gabbay, H., and Lev-Tov, A. (2004). Alpha-1 adrenoceptor agonists generate a "fast" NMDA receptor-independent motor rhythm in the neonatal rat spinal cord. J. Neurophysiol. 92, 997-1010.

Gordon, I. T., and Whelan, P. J. (2006). Monoaminergic control of caudaequina-evoked locomotion in the neonatal mouse spinal cord. J. Neurophysiol. 96, 3122-3129.

Han, P., Nakanishi, S. T., Tran, M. A., and Whelan, P. J. (2007). Dopaminergic modulation of spinal neuronal excitability. J. Neurosci. 27, 13192-13204

Hein, L. (2006). Adrenoceptors and signal transduction in neurons. Cell Tissue Res. 326, 541-551.

Jankowska, E., Gladden, M. H., and Czarkowska-Bauch, J. (1998). Modulation of responses of feline gamma-motoneurones by noradrenaline, tizanidine and clonidine. J. Physiol. 512(Pt. 2), 521-531.

Jordan, L. M., Liu, J., Hedlund, P. B., Akay, T., and Pearson, K. G. (2008). Descending command systems for the initiation of locomotion in mammals. Brain Res. Rev. 57, 183-191.

Kiehn, O. (2006). Locomotor circuits in the Mammalian spinal cord. Annu. Rev. Neurosci. 29, 279-306.

Kiehn, O., Hultborn, H., and Conway, B. A. (1992). Spinal locomotor activity in acutely spinalized cats induced by intrathecal application of noradrenaline. Neurosci. Lett. 143, 243-246.

Kiehn, O., Sillar, K. T., Kjaerulff, O., and McDearmid, J. R. (1999). Effects of noradrenaline on locomotor rhythm-generating networks in the isolated neonatal rat spinal cord. J. Neurophysiol. 82, 741-746.

Kitazawa, T., Saito, K., and Ohga, A. (1985). Effects of catecholamines on spinal motoneurones and spinal reflex discharges in the isolated spinal cord of the newborn rat. Brain Res. 351 , 31-36.

Kjaerulff, O., and Kiehn, O. (2001). 5 HT modulation of multiple inward rectifiers in motoneurons in intact preparations of the neonatal rat spinal cord. J. Neurophysiol. 85, 580-593.

Lapointe, N. P., Ung, R. V., Rouleau, P., and Guertin, P. A. (2008). Effects of spinal alpha(2)-adrenoceptor and I(1)-imidazoline receptor activation on hindlimb movemen induction in spinal cord-injured mice. J. Pharmacol. Exp. Ther. 325, 994-1006.

Li, X., Murray, K., Harvey, P. J., Ballou, E. W., and Bennett, D. J. (2007). Serotonin facilitates a persistent calcium current in motoneurons of rats with and without chronic spinal cord injury. J. Neurophysiol. 97, 1236-1246.

Machacek, D.W., and Hochman, S. (2006). Noradrenaline unmasks novel selfreinforcing motor circuits within the mammalian spinal cord. J. Neurosci. 26, 5920-5928.

Merrywest, S. D., Fischer, H., and Sillar, K. T. (2002). Alpha-adrenoreceptor activation modulates swimming via glycinergic and GABAergic inhibitory pathways in Xenopus laevis tadpoles. Eur. J. Neurosci. 15, 375-383.

Milner, T. A., Lee, A., Aicher, S. A., and Rosin, D. L. (1998). Hippocampal alpha2a-adrenergic receptors are located predominantly presynaptically but are also found postsynaptically and in selective astrocytes. J. Comp. Neurol. 395, 310-327.

Neher, E. (1992). Correction for liquid junction potentials in patch clamp experiments. Meth. Enzymol. 207, 123-131.

Parkis, M. A., Bayliss, D. A., and Berger, A. J. (1995). Actions of norepinephrine on rat hypoglossal motoneurons. J. Neurophysiol. 74, 1911-1919.

Parkis, M. A., and Berger, A. J. (1997). Clonidine reduces hyperpolarization-activated inward current (Ih) in rat hypoglossal motoneurons. Brain Res. 769, 108-118.

Queiroz, D. B., Porto, C. S., Grossman, G., Petrusz, P., and Avellar, M. C. (2008). Immunolocalization of alpha(1A)-adrenoceptors in rat and human epididymis. Cell Tissue Res. 332, 509-522.

Rauscent, A., Einum, J., Le Ray, D. Simmers, J., and Combes, D. (2009). Opposing aminergic modulation of distinct spinal locomotor circuits and their functional coupling during amphibian metamorphosis. $J$. Neurosci. 29, 1163-1174.

Rekling, J. C., Funk, G. D., Bayliss, D. A., Dong, X. W., and Feldman, J. L. (2000). Synaptic control of motoneuronal excitability. Physiol. Rev. 80, 767-852.

Remy-Neris, O., Barbeau, H., Daniel, O., Boiteau, F., and Bussel, B. (1999).Effects of intrathecal clonidine injection on spinal reflexes and human locomotion in incomplete paraplegic subjects. Exp. Brain Res. 129, 433-440.

Rossignol, S., Giroux, N., Chau, C. Marcoux, J., Brustein, E., and Reader, T. A. (2001). Pharmacological aids to locomotor training after spinal injury in the cat. J. Physiol. 533, 65-74.

Selvaratnam, S. R., Parkis, M. A., and Funk, G. D. (1998). Developmental modulation of mouse hypoglossal nerve inspiratory output in vitro by noradrenergic receptor agonists. Brain Res. 805, 104-115.

Sodickson, D. L., and Bean, B. P. (1996). GABAB receptor-activated inwardly rectifying potassium current in dissociated hippocampal CA3 neurons. J. Neurosci. 16, 6374-6385.

Sqalli-Houssaini, Y., and Cazalets, J. R. (2000). Noradrenergic control of locomotor networks in the in vitro spinal cord of the neonatal rat. Brain Res. 852, 100-109.

Takahashi, T. (1990). Inward rectification in neonatal rat spinal motoneurones. J. Physiol. 423, 47-62.

Van Hartesveldt, C., Sickles, A. E., Porter J. D., and Stehouwer, D. J. (1991). Ldopa-induced air-stepping in developing rats. Brain Res. Dev. Brain Res. 58, 251-255.

Conflict of Interest Statement: The authors declare that the research was conducted in the absence of any commercial 
or financial relationships that could be construed as a potential conflict of interest.

Received:09December 2009; paper pending published: 27 December 2009; accepted: 29
January 2010; published online: 08 March 2010.

Citation: Tartas M, Morin F, Barrière G, Goillandeau M, Lacaille J-C, Cazalets J$R$ and Bertrand SS (2010) Noradrenergic modulation of intrinsic and synaptic prop- erties of lumbar motoneurons in the neonatal rat spinal cord. Front. Neural Circuits

4:4. doi: 10.3389/neuro.04.004.2010

Copyright $@ 2010$ Tartas, Morin, Barrière, Goillandeau, Lacaille, Cazalets and Bertrand. This is an open-access article subject to an exclusive license agreement between the authors and the Frontiers Research Foundation, which permits unrestricted use, distribution, and reproduction in any medium, provided the original authors and source are credited. 